\title{
Editorial
}

Psychopathology

\section{More than Just Description: Phenomenology and Psychotherapy}

\author{
Thomas Fuchs $^{a}$ Guilherme Peres Messas ${ }^{b}$ Giovanni Stanghellini ${ }^{c, d}$ \\ ${ }^{a}$ Department of General Psychiatry, Center for Psychosocial Medicine, University of Heidelberg, Heidelberg,

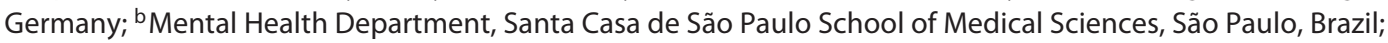 \\ 'Department of Psychological, Health and Territorial Sciences, G. d'Annunzio University, Chieti, Italy;

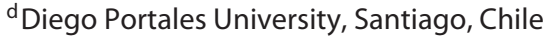

Since Jaspers' Allgemeine Psychopathologie [1], phenomenology has served as the foundational science for psychopathology, providing a rich framework for the assessment and analysis of subjective experience and its disturbances in mental disorders. The last two decades in particular have seen an international rise and progress of phenomenology in psychiatry, which is also demonstrated by the recent publication of the Oxford Handbook of Phenomenological Psychopathology [2]. Phenomenology is by no means restricted to the description of psychopathological phenomena, however. As an approach which investigates the patients' subjective and intersubjective experience, indeed their life world in a comprehensive way, it can go one step further and provide the basis for an extended understanding of psychiatric and psychotherapeutic practice [3]. This special issue of Psychopathology is meant to demonstrate the current interactions of phenomenology and psychotherapy on some crucial areas.

There are a number of specific contributions which phenomenology has to offer to the field of psychotherapy; we outline the most important ones:

- First, phenomenology has developed concepts of indepth psychopathological assessment and diagnosis which prepare the ground for further exploration in

\section{KARGER}

(c) 2019 S. Karger AG, Basel

E-Mail karger@karger.com

www.karger.com/psp the course of treatment [4-8]. Moreover, there are now semistructured phenomenological interviews which enable us to better understand the disturbed experiences of self and world in major psychiatric disorders (EASE [9]; EAWE [10]) as well as assessment scales which help to approximate the phenomenal core of severe mental conditions beyond epiphenomenal (i.e., behavioral) symptoms (e.g., IDEA [11]).

- The focus of phenomenological investigation and assessment lies on the prereflexive more than on the reflexive experience, on implicit more than on explicit forms of awareness. Thus, background phenomena such as atmospheres [12], existential feelings [13], common sense $[14,15]$ or anthropological disproportions $[16,17]$ come into view and enable a deeper understanding of what it is like to be in a given state of mental disturbance.

- A phenomenological approach implies a methodical suspension of our commonsensical assumptions about the shared world. This enables the psychotherapists to transpose themselves even into fundamentally different ways of finding oneself in the world, presupposing - in their endeavor to understand the patient - difference rather than resemblance between one's own way of experiencing the world and the other's [18]. 
This applies in particular to structural disturbances, in which the very constitution of reality and the overall ontological framework of experience is at stake, such as in schizophrenia [19].

- Phenomenology offers a view of social interaction that is primarily based on concepts of empathy, attunement, embodied resonance and intercorporeality instead of cognitivist notions such as "theory of mind" or "mind-reading" [20-22]. It thus can substantially contribute to our understanding of the psychotherapeutic relationship as an embodied encounter.

- While phenomenology and psychoanalysis have been rather opposed to one another for a long time, since they held divergent views on the possibility and role of the unconscious (e.g., Sartre [23]), recent years have seen an increasing dialogue and, to a certain extent, a convergence of both approaches to the human psyche. Phenomenology offers new ways of conceiving the unconscious as an embodied, relational or "horizontal" dimension, residing in the realms of intercorporeality and intersubjectivity $[24,25]$. Such concepts are in agreement with the current "relational turn" of psychoanalytic theory and can valuably inform psychotherapeutic practice.

- Finally, there has been a long and renowned tradition of transferring phenomenological concepts of beingin-the-world into existential and daseinsanalytic approaches of psychotherapy (Binswanger, Boss, Frankl, May and many others). These schools are still vivid today, but are also complemented by more recent existential-hermeneutic concepts based, among others, on human vulnerability and limit situations as basic conditions of mental disorders, and on the dialogical nature of existence [26-28].

In view of these and other contributions, phenomenology may well be regarded as a foundational science not only for psychopathological knowledge, but also for the theory and practice of psychotherapy. It provides an approach that captures human existence in all its dimensions, from self-awareness and embodiment (including their prereflexive and "unconscious" forms), to spatiality, temporality, narrativity and intersubjectivity. Moreover, it offers a view that localizes mental disorder neither in the hidden convolutions of the brain nor in the hidden corners of the patient's psyche, but rather in his lived experience and relations with others $[29,30]$.

As a consequence, psychotherapists inspired by phenomenology will move away from trying to change the inner states of the patient and instead focus on his implicit or explicit ways of interacting with others. And they will use the therapeutic relationship and dialogue as a means of changing his relationship patterns. Hence, from a phenomenological view, the process of psychotherapy is experiential, relational and embodied rather than cognitive, insight-oriented or "archaeological". The patient's habitual ways of relating to others are re-enacted in the "here and now" of the therapeutic situation and may be changed through new experiences. On such a view, it is not so much the explicit past that is in the focus of the therapeutic process, but rather the implicit past which organizes and structures the patient's phenomenal field of relating to others. The focus shifts from what happens inside the patient to what emerges from the in-between of patient and therapist.

These are only some first hints which should point out the direction of phenomenological thinking and practice in psychotherapy. By no means do we intend to declare a certain "phenomenological method" as mandatory. In this special issue, we rather present a variety of topics and approaches of current phenomenological authors, with a special focus on the treatment of psychosis:

1 Fuchs [31] develops a general concept of psychotherapy as being based on the phenomenal field, lived space, intercorporeality and body memory, corresponding to an embodied and ecological view of the mind.

2 Stanghellini [32] gives a synopsis of the "PHD" psychotherapy method, an integrative approach based on phenomenology $(\mathrm{P})$, hermeneutics $(\mathrm{H})$ and psychodynamics (D). It combines concepts of the life world with a dialectical view of psychopathology - which envisions the formation of symptoms as the outcome of the dynamics between the person and her vulnerability and with the dialogical principle of human existence.

3 Messas, Fukuda and Pienkos [33] present several phenomenological principles for a person-centered approach to substance misuse care. They emphasize the dialectic of anthropological proportions, involved in the existential situation of the substance misuser, and the dialect of decision, which is essential to all approaches to the treatment of substance misuse.

4 Fonagy, Luyten, Allison and Campbell [34] address the phenomenology of psychotherapy from the perspective of the theory of mentalizing and epistemic trust. They argue that intersubjective recognition in therapy enables the regulation and alignment of the patient's imaginative capacity with his or her phenomenological experiences.

5 D'Agostino, Mancini and Rossi Monti [35] discuss the most relevant areas of contemporary psychoanalysis in which phenomenology can claim a legitimate position: 
(a) the intersubjective matrix, in which human experience is embedded; (b) considering the "what" rather than the "why" of the patients' experience; and (c) the crisis of the primacy of interpretation in the analytical technique.

6 Tittarelli and Di Petta [36] offer a phenomenological approach to group therapy, focusing on the shared experience of "we-ness" and mutual presence, and on the conscious group processes instead of searching for hidden unconscious meanings beyond the phenomena.

7 Skodlar and Henriksen [37] undertake a translation of insights from the phenomenological psychopathology, highlighting what they call "core experiences" on the one hand and "experience-near concepts" on the other. On this basis, they offer a number of goals and strategies that may guide the therapeutic process.

8 Sass's paper [38] offers a hermeneutic-phenomenological perspective on three dangers relevant to the psychotherapy of schizophrenia: (1) neglecting the ontological horizon or overall framework dimension of altered experience; (2) overemphasizing the need for direct interpersonal interaction at the expense of appreciating the implicit, intersubjective sense of sharing perspectives; (3) overconfidence of one's ability to grasp the patient's subjectivity.

9 Lysaker, Dimaggio, Hamm, Leonhardt, Hochheiser and Lysaker [39] present a specific therapy for basic selfdisturbances in schizophrenia, called "metacognitive reflection and insight therapy" (MERIT), which is designed to target metacognition - defined as the process which makes available a sense of self and others within the flow of experience - and enhance the recovery of healthy self-experience.

10 Finally, Seikkula [40] interprets psychotic behavior as emerging in relationships that do not guarantee adequate responses, resulting in the patient's isolation from social relationships and odd behavior. If dialogical responses are guaranteed, recovery from psychotic behavior can occur; some guidelines for such dialogues are given.

In sum, we are confident that this special issue may give a convincing impression of the relevance of phenomenology for current psychotherapeutic approaches and that it can also stimulate further research and practice in this increasingly important field.

Thomas Fuchs, Guilherme Messas and Giovanni Stanghellini

\section{References}

1 Jaspers K. Allgemeine Psychopathologie. Ein Leitfaden für Studierende, Ärzte und Psychologen. Heidelberg: Springer; 1913.

2 Stanghellini G, Broome M, Raballo A, Fernandez AV, Fusar-Poli A, Rosfort R, editors. The Oxford handbook of phenomenological psychopathology. Oxford: Oxford University Press; 2019.

3 Tamelini M, Messas G. Pharmacological treatment of schizophrenia in light of phenomenology. Philos Psychiatry Psychol. 2019 Jun;26(2):133-42.

4 Kraus A. How can the phenomenological-anthropological approach contribute to diagnosis and classification in psychiatry? In: Fulford KW, Morris K, Sadler JZ, Stanghellini G, editors. Nature and narrative: an introduction to the new philosophy of psychiatry. Oxford: Oxford University Press; 2003. pp. 199-216.

5 Stanghellini G. The grammar of the psychiatric interview. A plea for the second-person mode of understanding. Psychopathology. 2007;40(2):69-74.

6 Fuchs T. Subjectivity and intersubjectivity in psychiatric diagnosis. Psychopathology. 2010;43(4):268-74.
7 Parnas J, Sass LA, Zahavi D. Rediscovering psychopathology: the epistemology and phenomenology of the psychiatric object. Schizophr Bull. 2013 Mar;39(2):270-7.

8 Messas G, Tamelini M. The pragmatic value of notions of dialectics and essence in phenomenological psychiatry and psychopathology. Thaumàzein Riv Filos. 2018;6:93-115.

9 Parnas J, Møller P, Kircher T, Thalbitzer J, Jansson L, Handest P, et al. EASE: examination of anomalous self-experience. Psychopathology. 2005 Sep-Oct;38(5):236-58.

10 Sass L, Pienkos E, Skodlar B, Stanghellini G, Fuchs T, Parnas J, et al. EAWE: examination of anomalous world experience. Psychopathology. 2017;50(1):10-54.

11 Stanghellini G, Castellini G, Brogna P, Faravelli $\mathrm{C}$, Ricca V. Identity and eating disorders (IDEA): a questionnaire evaluating identity and embodiment in eating disorder patients. Psychopathology. 2012;45(3):147-58.

12 Francesetti G, Griffero T, editors. Psychopathology and atmospheres: neither inside nor outside. Cambridge: Cambridge Scholars Publishing; 2019.

13 Ratcliffe M. Feelings of being. Phenomenology, psychiatry and the sense of reality. Oxford: Oxford University Press; 2008. https://doi. org/10.1093/med/9780199206469.001.0001.
14 Blankenburg W, Mishara AL. First steps toward a psychopathology of "common sense". Philos Psychiatry Psychol. 2001;8(4):303-15.

15 Stanghellini G. Disembodied spirits and deanimated bodies: the psychopathology of common sense. Oxford: Oxford University Press; 2004. https://doi.org/10.1093/med/ 9780198520894.001.0001.

16 Blankenburg W. A dialectical conception of anthropological proportions. In: De Koonig A, Jenner F, editors. Phenomenology and psychiatry. London: Academic Press; 1982. p. 3550.

17 Messas G, Garcia Tamelini M, Cutting J. A meta-analysis of the core essence of psychopathological entities: an historical exercise in phenomenological psychiatry. Hist Psychiatry. 2017 Dec;28(4):473-81.

18 Stanghellini G, Rosfort R. Empathy as a sense of autonomy. Psychopathology. 2013;46(5): 337-44.

19 Messas G, Tamelini M, Mancini M, Stanghellini G. New perspectives in phenomenological psychopathology: its use in psychiatric treatment. Front Psychiatry. 2018 Sep;9:466.

20 Zahavi D. Empathy and direct social perception: a phenomenological proposal. Rev Phil Psychol. 2011;2(3):541-58. 
21 Ratcliffe M. Phenomenology as a form of empathy. Inquiry. 2012;55(5):473-95.

22 Fuchs T. Intercorporeality and interaffectivity. In: Meyer C, Streeck J, Jordan S, editors. Intercorporeality: emerging socialities in interaction. Oxford: Oxford University Press; 2017. p. 3-24. https://doi.org/10.1093/acprof: oso/9780190210465.003.0001.

23 Sartre JP (Barnes HE, translator). Being and nothingness. New York: Philosophical Library; 1956.

24 Fuchs T. Body memory and the unconscious. In: Gipps R, Lacewing M, editors. The Oxford handbook of philosophy and psychoanalysis. Oxford: Oxford University Press; 2019. p. $457-70$.

25 Lacewing M. How should we understand the psychoanalytic unconscious? In: Gipps R, Lacewing M, editors. The Oxford handbook of philosophy and psychoanalysis. Oxford: Oxford University Press; 2019. p. 407-31.

26 Fuchs T. Existential vulnerability: toward a psychopathology of limit situations. Psychopathology. 2013;46(5):301-8.

27 Holzhey-Kunz A. Daseinsanalysis. London: Free Association Books; 2014.

28 Stanghellini G. Lost in dialogue: anthropology, psychopathology, and care. Oxford: Oxford University Press; 2016. https://doi. org/10.1093/med/9780198792062.001.0001.
29 Stanghellini G, Aragona M. Phenomenological psychopathology: toward a person-centered hermeneutic approach in the clinical encounter. In: Stanghellini G, Aragona M, editors. An experiential approach to psychopathology: what is it like to suffer from mental dis-orders? Berlin, Heidelberg, New York: Springer; 2016. pp. 1-43.

30 Fuchs T. Ecology of the brain. The phenomenology and biology of the embodied mind. Oxford: Oxford University Press; 2017. h t tps://doi.org/10.1093/med/ 9780199646883.001.0001.

31 Fuchs T. The interactive phenomenal field and the life space. Sketch of an ecological concept of psychotherapy. Psychopathology. 2019;52:67-74.

32 Stanghellini G. The PHD method for psychotherapy: integrating phenomenology, hermeneutics and psychodynamics. Psychopathology. 2019;52:75-84.

33 Messas G, Fukuda L, Pienkos E. A phenomenological contribution to substance misuse treatment: principles for comprehensive care. Psychopathology. 2019;52:85-93.
34 Fonagy P, Luyten P, Allison E, Campbell C. Mentalizing, epistemic trust and the phenomenology of psychotherapy. Psychopathology. 2019;52:94-103.

35 D’Agostino A, Mancini M, Rossi Monti M. Phenomenology in psychoanalysis: still an open debate? Psychopathology. 2019;52: 104-9.

36 Tittarelli D, Di Petta G. The "we-ness" in the dasein-group analysis. Psychopathology. 2019;52:110-16.

37 Škodlar B, Henriksen MG. Toward a phenomenological psychotherapy for schizophrenia. Psychopathology. 2019;52:117-25.

38 Sass L. Three dangers: phenomenological reflections on the psychotherapy of psychosis. Psychopathology. 2019;52:126-34.

39 Lysaker PH, Dimaggio G, Hamm JA, Leonhardt BL, Hochheiser J, Lysaker JT. Disturbances in self-experience in schizophrenia: metacognition and the development of an integrative recovery-oriented individual psychotherapy. Psychopathology. 2019;52:13542.

40 Seikkula J. Psychosis is not illness but a survival strategy in severe stress: a proposal for an addition to a phenomenological point of view. Psychopathology. 2019;52:143-50. 